\title{
The 10 remaining mysteries of inflammatory bowel disease
}

\author{
Jean-Frédéric Colombel, ${ }^{1}$ Alastair J M Watson, ${ }^{2}$ \\ Markus F Neurath ${ }^{3}$
}

Tremendous progress has been made in our understanding of the pathobiology of inflammatory bowel disease (IBD: Crohn's disease (CD) and ulcerative colitis (UC)) through research on mouse models of gut inflammation, human population genetics studies and immunological research. ${ }^{1-4}$ However, despite these important advances, many of the primary features of human IBD remain unexplained.

In this article we pose a series of 10 fundamental questions about the epidemiology and clinical course of IBD that remain unanswered to this day. In order to obtain "best guess" answers to these questions, we have interviewed experts who are leaders in the field of each question. This article is a distillation of their opinions which we hope will refocus future research onto these remaining mysteries (Box 1) which are essential for improving the clinical management of IBD.

\section{WHAT EXPLAINS THE GEOGRAPHICAL AND HISTORICAL VARIATION IN THE INCIDENCE OF IBD?}

The incidence of IBD has risen sharply in the last 50 years in the USA and western European countries; with the increase occurring in higher social classes before lower social classes. ${ }^{56}$ The increase in incidence is too rapid to be accounted for by genetic changes and strongly points to changes in environmental risk factors, especially changes in diet and intestinal microflora. ${ }^{7}$ In Japan, a correlation between incidence of IBD and fat and meat intake has been reported. ${ }^{8}$ Changes in diet and food preparation could influence intestinal microflora. Large variations in the range of bacterial lineages within the intestines of different individuals have been reported. ${ }^{9}$

\footnotetext{
${ }^{1}$ Hôpital Claude Huriez, Centre Hospitalier Universitaire de Lille, Lille, France; ${ }^{2}$ School of Clinical Sciences, University of Liverpool, Liverpool, UK; ${ }^{3}$ First Medical Clinic, University of Mainz, Mainz, Germany
}

Correspondence to: Professor Alastair Watson, School of Clinical Sciences, The Henry Wellcome Laboratory, Nuffield Building, University of Liverpool, Crown Street, Liverpool L69 3BX, UK; Alastair.watson@liv.ac.uk
However, the relationship between the microbial community structure within the gut and IBD is unknown. New concepts that intestinal microbiota exist in a finely balanced ecosystem in which changes to one microbial species influences other species suggest that ideas that IBD is caused by a single microbial species may be oversimplistic. ${ }^{10}$

The advent of refrigeration in the early 20th century promoting Yersinia and Listeria spp in food has been proposed to account for the rise in IBD. ${ }^{11}$ Certain Escherichia coli strains are also associated with $\mathrm{CD}$, though their relationship to food is not known. ${ }^{12}$ Debates and investigations continue into a putative aetiological role for mycobacteria despite the paucity of compelling evidence to support this hypothesis. ${ }^{13}$ The "hygiene" hypothesis proposes that lack of stimulation of the immune system by environmental microorganisms and antigens in childhood may predispose to IBD. ${ }^{14}$ Commensal gut organisms can stimulate regulatory $\mathrm{T}$ cells and prevent IBD in a mouse model. ${ }^{15}$ Further support for changes in intestinal microflora comes from the observation that antibiotic use is associated with the onset of CD. ${ }^{16}$

\section{Box 1 The 10 remaining mysteries of inflammatory bowel disease}

- What explains the geographical and historical variation in the incidence of inflammatory bowel disease?

- Why is appendicitis associated with a reduced risk of ulcerative colitis?

- Why does smoking exacerbate Crohn's disease but protects against ulcerative colitis?

- Why is the inflammation of Crohn's disease transmural and that of ulcerative colitis confined to the mucosa, and how does it drive cancer?

- Are ulcerative colitis and Crohn's disease distinct disorders or part of a continuum?

- Why does Crohn's disease have skip lesions down the entire gastrointestinal tract?

- What is the role of extraluminal structures (mesenteric fat, vasculature, lymphatics) in Crohn's disease?

- What are the factors that determine the timing of the initial attack of inflammatory bowel disease and subsequent relapses?

- Why does postoperative recurrence of Crohn's disease usually occur in the neo-terminal ileum?

- Why are certain extraintestinal manifestations linked to the evolution of inflammatory bowel disease and some are independent? 


Experts contributing to this article
Ted Bayless, Baltimore; Richard
Blumberg, Boston; Jacques Cosnes,
Paris; Geert D'Haens, Leuven; Anders
Ekbom, Stockholm; Morten Frisch,
Copenhagen; Karel Geboes, Leuven;
Hans Herfarth, Chapel Hill; Derek Jewell,
Oxford; Herbert Van Kruiningen, Hartford;
Laurent Peyrin-Biroulet, Lille; Daniel
Podolsky, Boston; Graham Radford-
Smith, Brisbane, Jonathan Rhodes,
Liverpool; Robert Riddell, Toronto; David
Sachar, New York; Juergen Schoelmerich,
Regensburg; Eduard Stange, Stuttgart;
Warren Strober, Bethesda.

\section{WHY DOES SMOKING EXACERBATE CD BUT PROTECTS AGAINST UC??}

A number of plausible hypotheses have been proposed to answer this question but none has been proven. This dichotomy may simply be a result of smoking having different effects on the small and large intestine. ${ }^{28}$ In $\mathrm{CD}$, macrophage dysfunction and impaired phagocytosis may play a pathogenic role. ${ }^{2}$ Pulmonary macrophages from smokers have impaired killing of intracellular bacteria, raising the possibility that smoking also impairs macrophage function in the gut. ${ }^{29}$ Carbon monoxide from smoking may augment microvascular abnormalities documented in CD. ${ }^{30}{ }^{31}$ Inadequate apoptosis of $\mathrm{T}$ cells contributes to the persistent inflammatory responses of $\mathrm{CD}$, though this may be a feature of any chronic inflammatory response..$^{32} 33$ Nitrosamine 4-(methylnitrosamino)-1-(3pyridyl)-1-butanone (NNK), the most potent carcinogen in cigarette smoke, may further inhibit $\mathrm{T}$ cell apoptosis through phosphorylation of bcl-2 and myc. ${ }^{34}$ In contrast, in UC excessive apoptosis of colonic epithelial cells may be a significant factor. ${ }^{35}$ In this case, the antiapoptotic effects of cigarette smoke would be beneficial. Carbon monoxide is known to have anti-inflammatory effects mediated by interleukin (IL) 10 but is also beneficial in the IL10 knockout mouse model of colitis via a mechanism involving the induction of haem-oxidase-1. . $^{36}{ }^{37}$ Further beneficial effects may be via increasing mucin production, ${ }^{38}$ reducing expression of IL $8^{39}$ or inhibiting tumour necrosis factor (TNF) production. ${ }^{37}$ Overall, the effect of smoking on IBD may be the sum of contradictory effects exacerbating chronic inflammation via impaired vascular perfusion but improving acute colitis.

\section{WHY IS THE INFLAMMATION OF CD TRANSMURAL AND THAT OF UC CONFINED TO THE MUCOSA, AND HOW DOES IT DRIVE CANCER?}

It is stated in the majority of IBD textbooks that CD causes a transmural, granulomatous gut inflammation, whereas inflammation in UC is restricted to the mucosa. The pathologists in the expert panel did not feel this dogma was true, ${ }^{40} 41$ as CD may be limited to mucosal aphthoid lesions and severe UC may cause submucosal or even transmural inflammation (eg, toxic megacolon). However, there was general consensus that CD inflammation frequently goes further into the mucosa than UC inflammation. The experts suggests that this observation is due to the fundamentally different aetiology of the two diseases. ${ }^{142} 43$ One scenario suggests that UC is a disease of the epithelium (possibly of autoimmune origin) that drives inflammation close to the epithelial cell layer, whereas CD is a disease of the mucosal barrier in a genetically susceptible host that results in activation of the innate and later adaptive mucosal immune systems in deeper layers of the gut. ${ }^{42}{ }^{44}$ Other experts suggested that in CD, but not UC, intestinal phagocytes fail to kill or neutralise the invading pathogens, thereby causing a perpetuated translocation of bacteria into the bowel wall (possibly through altered barrier function or the defective autophagy genes ATG16L1 and $I G^{45}$ ). Thus $C D$ may bear analogies to a localised infection that progresses into the bowel wall until the infection is at least partially controlled by the mucosal immune system. Other ideas include defective mucosal antiprotease activity in CD but not UC, ${ }^{46}$ lymphatic obstruction in CD but not UC, and different types of bacteria causing CD and UC (eg, adhesive bacteria causing superficial inflammation in $\mathrm{UC}$ vs more invasive bacteria in $\mathrm{CD}^{47}$ ).

Remarkable recent observations highlight the importance of bacterial flora in UC. Mice lacking both lymphocytes and T-bet, a transcription factor that regulates immune cell differentiation and function, develop colonic inflammation that closely mimics UC. This is mediated by TNF production and loss of intestinal epithelial barrier function. Microbial flora from such mice cause a similar colitis when given to mice with a normal immune system, demonstrating that the host immune response can modify the intestinal microbial ecosystem so that it becomes colitogenic. ${ }^{48}$

Finally, debate remains as to whether cancer risk is greater in UC than CD. If one assumes that UC causes cancer development frequently, ${ }^{49}$ potential reasons comprise the primary epithelial origin of UC with frequent ulcer formation that may cause proliferation, oxidative stress and DNA damage in epithelial cells. In this way, the inflammation together with primary epithelial defects may trigger carcinogenesis in $\mathrm{UC}^{50}$ the risk factors being flare frequency and extent of disease.

\section{ARE UC AND CD DISTINCT DISORDERS OR PART OF A CONTINUUM?}

The different distributions of inflammation along the gastrointestinal (GI) tract in UC and CD suggest they may have different disease mechanisms. The opposite effects of smoking on UC and CD lend further support. The concept that UC is always confined to the colon was disputed by our expert pathologists. In fact, severe UC may cause backwash ileitis, and UC in some children may result in superficial mucosal inflammation of the entire small intestine or duodenitis. ${ }^{51}$ Furthermore, UC in children can be associated with diffuse and focally enhanced Helicobacter pylori-negative gastritis. ${ }^{52}$ It is thus possible that UC (at least in a subgroup of patients) starts as a more widespread disease with upper and lower GI involvement and that the lesions in the upper GI tract disappear while those in the lower GI tract persist.

There is genetic evidence that extensive UC may be a distinct disease subgroup of UC as IBD2 is associated with extensive UC but not distal disease. ${ }^{53}$ The tendency for UC to be confined to the colon in contrast to $\mathrm{CD}$ may have several reasons. ${ }^{35} 54$ (1) In UC the changes in immune response may be sufficiently subtle that the trigger required for inflammation can only be provided by the large bacterial load in the colon. In contrast, a far less intense trigger may be required for $\mathrm{CD}$ and so can occur anywhere in the GI tract. (2) UC originates from the rectum as this region may be most conducive to the induction of the cytokine milieu necessary for pathological natural killer (NK) T cell development (eg, IL13 ${ }^{35}$ ) and colonic, but not small intestinal epithelial cells, may produce UC-inducing cytokines. (3) Differences in the vasculature, mucus production or the commensal microflora between the colon and small intestine could cause the regional differences in UC and CD. (4) Differences in the expression of receptors for diseasecausing antigens could be present between the colon and the small intestine (eg, pathogen-associated molecular patterns, Toll-like receptors), thereby preventing 
small intestinal inflammation. (5) Genetic predispositions in UC may affect genes that are mainly expressed and functionally relevant in the colon. The sharp demarcation between involved and uninvolved areas in UC is an endoscopic observation but may not be reflected by histology in all patients. Furthermore, the concept of continuous inflammation in UC may not be true in all patients, since there can be rectal sparing in subgroups of UC patients (eg, PSC-IBD ${ }^{55}$ ), leading to absence of continuous mucosal inflammation of the colon.

\section{WHY DOES CD HAVE SKIP LESIONS DOWN THE ENTIRE GI TRACT?}

The discontinuous inflammation of the GI tract with skip lesions has been described as a hallmark feature of CD. Segmental mucosal inflammation is characteristic of many infectious forms of colitis (eg, tuberculosis, cytomegalovirus infection, amoebiasis). CD might be considered as an atypical infectious disease in which the host responds inappropriately to some elements of the commensal microflora. ${ }^{42} 445657$ The segmental nature of inflammation in CD could therefore be due to the topology of the commensal microflora colonisation and the topology of the immune response (eg, receptor expression levels) and their mutual interactions. This concept is supported by the finding that different bacterial species cause inflammation in different segments of the GI tract in IL10-deficient mice. ${ }^{58}$ Other factors such as the segmental nature of the vascular and nerve supply, regional variation in lymphatics and $M$ cells, stasis of luminal contents, deficiency in $\alpha$-defensin in the ileum ${ }^{59}$ and the production of mediators that prevent lateral spreading of disease could all contribute to the development of skip lesions in CD. Recent studies of genetic polymorphisms suggest that ileal and colonic disease may be distinct. The majority of patients with single nucleotide polymorphisms that associate with $\mathrm{CD}$ have ileal disease. The exception to this is that IBD5 has been reported to be associated with perianal disease in CD. ${ }^{60}$

\section{WHAT IS THE ROLE OF EXTRALUMINAL STRUCTURES (MESENTERIC FAT, VASCULATURE, LYMPHATICS) IN CD?}

It is generally believed that changes in extraluminal structures are just markers of transmural inflammation. However, there is evidence that mesenteric fat and vasculature participate in the pathogenesis of CD. Mesenteric fat hypertrophy is a hallmark of CD. ${ }^{61-63}$ It is an important source of $\mathrm{TNF} \alpha$, which could explain the location of mucosal ulcerations along the mesenteric border. ${ }^{64}$ Adipocytes express C-reactive protein (CRP) and there is a significant correlation between serum CRP levels and increased mesenteric fat density in CD. ${ }^{65}$ Mesenteric fat may also contribute to innate immunity by limiting intestinal bacterial translocation, as illustrated by increased adiposity following viral infection and its expression of NOD2 and Toll-like receptors. ${ }^{63}$ The hypothesis that the primary pathological abnormality in CD is in the mesenteric blood supply has not been confirmed. ${ }^{30}$ Whether increased vascularisation as assessed by mesenteric angiography or Doppler ultrasound reflects CD activity is disputed. ${ }^{66}$ Recent evidence for angiogenesis playing a role in IBD pathogenesis has prompted interest in antiangiogenic therapies for IBD. ${ }^{67}{ }^{68}$ Finally, the microscopic appearance and distribution of $\mathrm{CD}$ lesions strongly suggests that lymphangitis plays a role in the pathology of CD..$^{69} 70$ This has been almost completely ignored in the recent literature. Once rediscovered, aetiologists may choose to focus their attention on agents that target the lymphatic endothelium.

\section{WHAT ARE THE FACTORS THAT DETERMINE THE TIMING OF THE INITIAL ATTACK OF IBD AND SUBSEQUENT RELAPSES?}

It is difficult to determine when IBD actually starts, as significant inflammation can be present before there is sufficient luminal compromise or systemic effects to cause symptoms. Increased intestinal permeability and appearance of serological markers have been shown to precede the development of overt CD. ${ }^{71}{ }^{72}$ What then triggers the first symptomatic "attack"? CD often occurs at a time in life when teenagers and young adults are at risk for several infectious diseases, including, tonsillitis, appendicitis, mononucleosis and Hodgkin's disease. This is also the time when the Peyer's patches and lymphoid follicles of the small intestine "the tonsils of the lower intestine" are at their greatest number and probably at their greatest activity. $^{73}$ The initial insult may be an enteric virus entering Peyer's patches in a susceptible host. Relapses can occur after the withdrawal of medication, especially if there is evidence of continued inflammation such as elevated sedimentation rate, CRP or mucosal concentration of TNF. ${ }^{74}$ There have been a number of reports of seasonality of relapses of IBD. ${ }^{76}$ Flare-ups may be induced by viruses other than that which may have initiated the disease, or by bacteria. ${ }^{77} 78$ Animal and clinical epidemiological studies also lend support for psychological stress contributing to relapse in IBD, though some studies have been flawed by poor design and analysis. $^{79}$

\section{WHY DOES POSTOPERATIVE RECURRENCE OF CD USUALLY OCCUR IN THE NEO-TERMINAL ILEUM?}

Observational studies have demonstrated that CD recurs in up to $90 \%$ of patients in the years following "curative" surgery. ${ }^{80} 81$ In the case of ileocolonic anastomosis, the vast majority of recurrences take place in the neo-terminal ileum, just proximal to the anastomosis. ${ }^{80} 81$ Resection usually removes the ileocaecal valve, creating the potential for the contents of the colon to be shared with the neo-terminal ileum. Recurrence may just be the consequence of increased exposure of susceptible Peyer's patches to luminal agents. After ileocolectomy, bacterial colonisation of the neo-terminal ileum is increased. ${ }^{82}$ Primary ileostomies have a lower risk of recurrence than ileocolonic anastomosis. ${ }^{83}$ Reinfusion studies have shown that when ileal fluid is infused across an ileocolonic anastomosis via double-loop ileostomy, signs of inflammation appear within 1 week, but only if the fluid contains bacteria. $^{84}{ }^{85}$ Surgical resection inevitably interrupts lymphatics at the site where the anastamosis is performed. The intestinal segment proximal to where the resection was performed may, in fact, have lymphangitis. ${ }^{86}$ The resulting oedematous Peyer's patches and localised lymphangiectasia could be prime sites for recurrence and microbial-induced fissures and fistulae. ${ }^{69}$ Another factor is the specific role of particular bacterial subpopulations. An increased number of adherent invasive $E$ coli adhere to the ileal mucosa of patients with CD both before and after surgery. ${ }^{87}$ This results in increased expression of CEACAM6, a protein known to enhance bacterial adhesion, including adherent invasive $E$ coli ${ }^{88} \mathrm{~A}$ deficiency of $\boldsymbol{\alpha}$-defensin in the ileum may be a further localising factor. ${ }^{59}$

\section{WHY ARE CERTAIN EXTRAINTESTINAL MANIFESTATIONS LINKED TO THE EVOLUTION OF IBD AND SOME ARE INDEPENDENT?}

The most common extraintestinal manifestations (EIMs) relate to the joints and eyes, along with some skin manifestations such as erythema nodosum and pyoderma gangrenosum. ${ }^{89}$ The aetiology of EIMs is 
thought to be a combination of genetic predisposition and exposure to luminal bacterial content. The relationship of some EIMs to disease activity may be the result of more bacterial antigens being presented to the systemic immune system because of increased intestinal permeability during active disease. ${ }^{89}$ A strong association has been observed between EIMs involving the joints and eyes and the human leucocyte antigen (HLA) locus on the short arm of chromosome $6 .{ }^{90}$ For instance, peripheral arthritis is more frequent in patients with HLADRB1*0103. ${ }^{91}$ As major histocompatibility complex (MHC) class II molecules are involved in antigen presentation, this association further suggests a key role for luminal antigens in the pathogenesis of these EIMs. In contrast, the progress of ankylosing spondylitis (AS) is independent of the activity of bowel disease. There is a strong genetic component in AS which is conferred by HLA- $B^{*} 27$. Bacteria may be important in the initiation of IBDassociated AS, but once the disease has started it runs its course independently. There is also a lack of association between the severity of IBD and the likelihood of developing primary sclerosing cholangitis (PSC). ${ }^{92}$ Bacteria have not been convincingly demonstrated to play a pathogenic role. It has been proposed that PSC could be mediated by long-lived memory T cells incorrectly expressing CCL25, causing them to home to hepatic endothelium in the absence of active IBD. ${ }^{93}$

\section{CONCLUSION}

Astonishing advances have been made in our understanding of IBD in recent years, and it would not have been possible to contemplate answering the questions posed above 10 years ago. Nevertheless, these apparently simple questions remain substantially unsolved. Our panel of experts have provided extraordinarily wide-ranging and authoritative opinions on the answers to our questions. We sincerely thank them and apologise if we have not fully reflected their views. We have tried to be provocative in this article in order to open new avenues of research, and we welcome feedback, especially from readers who disagree with our views on IBD.

Modern therapy, especially biological therapy, is both expensive and potentially dangerous, and yet only a subgroup of IBD patients gain significant clinical benefit. ${ }^{94}$ We have little idea how to select and predict response to therapy in individual patients. We believe that in answering our 10 questions, significant advances will be made towards making personalised medicine for IBD a clinical reality. IBD research is now exceptionally dynamic, and we hope that in 10 years time the true answers to our questions will become available.

Competing interests: None.

Revised 27 October 2007

Accepted 13 November 2007

Published Online First 13 December 2007

Gut 2008;57:429-433. doi:10.1136/gut.2007.122192

\section{REFERENCES}

1. Xavier RJ, Podolsky DK. Unravelling the pathogenesis of inflammatory bowel disease. Nature 2007:448:427-34.

2. Wellcome Trust Case Control Consortium Genome-wide association study of 14,000 cases of seven common diseases and 3,000 shared controls. Nature 2007; 447:661-78.

3. Duerr RH, Barmada MM, Zhang L, et al. Evidence for an inflammatory bowel disease locus on chromosome 3p26: linkage, transmission/disequilibrium and partitioning of linkage. Hum $\mathrm{Mol}$ Genet 2002;11:2599-606.

4. Parkes M, Barrett JC, Prescott NJ, et al. Sequence variants in the autophagy gene IRGM and multiple other replicating loci contribute to Crohn's disease susceptibility. Nat Genet 2007;39:830-2.

5. Russel MG. Changes in the incidence of inflammatory bowel disease: what does it mean? Eur J Intern Med 2000;11:191-196.

6. Danese S, Sans M, Fiocchi C. Inflammatory bowel disease: the role of environmental factors. Autoimmun Rev 2004;3:394-400

7. Shoda R, Matsueda K, Yamato S, et al. Epidemiologic analysis of Crohn disease in Japan: increased dietary intake of $n-6$ polyunsaturated fatty acids and animal protein relates to the increased incidence of Crohn disease in Japan. Am J Clin Nutr 1996:63:741-5.

8. Sakamoto N, Kono S, Wakai K, et al. Dietary risk factors for inflammatory bowel disease: a multicenter case-control study in Japan. Inflamm Bowel Dis 2005;11:154-63.

9. Ley RE, Turnbaugh PJ, Klein S, et al. Microbial ecology: human gut microbes associated with obesity. Nature 2006;444:1022-3.

10. Turnbaugh PJ, Ley RE, Hamady M, et al. The human microbiome project. Nature 2007;449:804-10.

11. Hugot JP, Alberti C, Berrebi D, et al. Crohn's disease: the cold chain hypothesis. Lancet 2003;362:2012-5.

12. Rhodes JM. The role of Escherichia coli in inflammatory bowel disease. Gut 2007;56:610-2.

13. Peyrin-Biroulet L, Neut C, Colombel JF. Antimycobacterial therapy in Crohn's disease: game over? Gastroenterology 2007;132:2594-8.

14. Garn H, Renz H. Epidemiological and immunological evidence for the hygiene hypothesis. Immunobiology 2007;212:441-52

15. Di Giacinto C, Marinaro M, Sanchez M, et al. Probiotics ameliorate recurrent Th1-mediated murine colitis by inducing IL-10 and IL-10-dependent TGFbeta-bearing regulatory cells. J Immunol 2005;174:3237-46.

16. Card T, Logan RF, Rodrigues LC, et al. Antibiotic use and the development of Crohn's disease. Gut 2004;53:246-50.

17. Andersson RE, Olaison G, Tysk C, et al. Appendectomy and protection against ulcerative colitis. N Engl J Med 2001;344:808-14.

18. Andersson RE. Inverse association between appendectomy and ulcerative colitis. Surgery 2002;131:472; author reply 472-3.

19. Kaplan GG, Pedersen BV, Andersson RE, et al. The risk of developing Crohn's disease after an appendectomy: a population-based cohort study in Sweden and Denmark. Gut 2007.
20. Kawachiya T, Oshitani N, Jinno Y, et al. Significance of increased proliferation of immature plasma cells in the appendix of patients with ulcerative colitis. Int J Mol Med 2005:15:417-23.

21. Fujihashi K, McGhee JR, Lue C, et al. Human appendix B cells naturally express receptors for and respond to interleukin 6 with selective $\lg A 1$ and $\lg A 2$ synthesis. J Clin Invest 1991;88:248-52.

22. Mizoguchi A, Mizoguchi E, Chiba C, et al. Role of appendix in the development of inflammatory bowel disease in TCR-alpha mutant mice. J Exp Med 1996;184:707-15.

23. Sakamaki S, Takayanagi N, Yoshizaki N, et al. Autoantibodies against the specific epitope of human tropomyosin(s) detected by a peptide based enzyme immunoassay in sera of patients with ulcerative colitis show antibody dependent cell mediated cytotoxicity against HLA-DPw9 transfected L cells. Gut 2000; 47:236-41.

24. Kovvali G, Das KM. Molecular mimicry may contribute to pathogenesis of ulcerative colitis. FEBS Lett 2005;579:2261-6.

25. Mudter J, Neurath MF. II-6 signaling in inflammatory bowel disease: pathophysiological role and clinical relevance. Inflamm Bowel Dis 2007;13:1016-23.

26. Ruber M, Berg A, Ekerfelt C, et al. Different cytokine profiles in patients with a history of gangrenous or phlegmonous appendicitis. Clin Exp Immunol 2006;143:117-24.

27. Thomas GA, Rhodes J, Green JT. Inflammatory bowel disease and smoking - a review. Am J Gastroenterol 1998;93:144-9.

28. Karban A, Eliakim R. Effect of smoking on inflammatory bowel disease: is it disease or organ specific? World J Gastroenterol 2007;13:2150-2.

29. King TE, Jr., Savici D, Campbell PA. Phagocytosis and killing of Listeria monocytogenes by alveolar macrophages: smokers versus nonsmokers. J Infect Dis 1988;158:1309-16

30. Wakefield AJ, Sawyerr AM, Dhillon AP, et al. Pathogenesis of Crohn's disease: multifocal gastrointestinal infarction. Lancet 1989;2:1057-62.

31. Hatoum $\mathbf{O A}$, Binion DG, Otterson MF, et al. Acquired microvascular dysfunction in inflammatory bowel disease: loss of nitric oxide-mediated vasodilation. Gastroenterology 2003;125:58-69.

32. Watson AJ. In vivo single-photon emission computed tomography imaging of apoptosis in Crohn's disease and anti-tumour necrosis factor therapy. Gut 2007:56:461-3.

33. Boirivant M, Marini M, Di Felice G, et al. Lamina propria T cells in Crohn's disease and other gastrointestinal inflammation show defective CD2 pathway-induced apoptosis. Gastroenterology 1999:116:557-65.

34. Jin Z, Gao F, Flagg T, Deng X. Tobacco-specific nitrosamine 4-(methylnitrosamino)-1-(3-pyridyl)-1butanone promotes functional cooperation of Bcl2 and c-Myc through phosphorylation in regulating cell survival and proliferation. $J$ Biol Chem 2004:279:40209-19.

35. Heller F, Florian P, Bojarski C, et al. Interleukin-13 is the key effector Th2 cytokine in ulcerative colitis that affects epithelial tight junctions, apoptosis, and cell restitution. Gastroenterology 2005;129:550-64.

36. Hegazi RA, Rao KN, Mayle A, et al. Carbon monoxide ameliorates chronic murine colitis through a heme oxygenase 1-dependent pathway. J Exp Med 2005:202:1703-13.

37. Sadis C, Teske G, Stokman G, et al. Nicotine protects kidney from renal ischemia/reperfusion injury through the cholinergic anti-inflammatory pathway. PLOS ONE 2007;2:e469.

38. Finnie IA, Campbell BJ, Taylor BA, et al. Stimulation of colonic mucin synthesis by corticosteroids and nicotine. Clin Sci (Lond) 1996;91:359-64.

39. Louvet B, Buisine MP, Desreumaux $P$, et al. Transdermal nicotine decreases mucosal IL-8 expression but has no effect on mucin gene expression in ulcerative colitis. Inflamm Bowel Dis 1999;5:174-81.

40. Geboes K. Is histology useful for the assessment of the efficacy of immunosuppressive agents in IBD and 
if so, how should it be applied? Acta Gastroenterol Belg 2004;67:285-9.

41. Guindi M, Riddell RH. Indeterminate colitis. J Clin Pathol 2004:57:1233-44.

42. Strober W, Fuss I, Mannon P. The fundamental basis of inflammatory bowel disease. J Clin Invest 2007:117:514-21.

43. Neurath MF, Finotto S, Glimcher LH. The role of Th1/ Th2 polarization in mucosal immunity. Nat Med 2002;8:567-73.

44. Strober W, Fuss IJ, Blumberg RS. The immunology of mucosal models of inflammation. Annu Rev Immunol 2002; 20:495-549.

45. Rioux JD, Xavier RJ, Taylor KD, et al. Genome-wide association study identifies new susceptibility loci for Crohn disease and implicates autophagy in disease pathogenesis. Nat Genet 2007;39:596-604.

46. Schmid M, Fellermann K, Fritz P, et al. Attenuated induction of epithelial and leukocyte serine antiproteases elafin and secretory leukocyte protease inhibitor in Crohn's disease. J Leukoc Biol 2007:81:907-15.

47. Martin HM, Campbell BJ, Hart CA, et al. Enhanced Escherichia coli adherence and invasion in Crohn's disease and colon cancer. Gastroenterology 2004;127:80-93.

48. Garrett WS, Lord GM, Punit S, et al. Communicable ulcerative colitis induced by T-bet deficiency in the innate immune system. Cell 2007:131:33-45.

49. Ullman T, Croog V, Harpaz N, et al. Progression of flat low-grade dysplasia to advanced neoplasia in patients with ulcerative colitis. Gastroenterology 2003;125:1311-9.

50. Greten FR, Eckmann L, Greten TF, et al. IKKbeta links inflammation and tumorigenesis in a mouse model of colitis-associated cancer. Cell 2004;118:285-96.

51. Valdez R, Appelman HD, Bronner MP, et al. Diffuse duodenitis associated with ulcerative colitis. Am J Surg Pathol 2000;24:1407-13.

52. Sharif $\mathbf{F}, \mathbf{M c D e r m o t t} \mathbf{M}$, Dillon $\mathrm{M}$, et al. Focally enhanced gastritis in children with Crohn's disease and ulcerative colitis. Am J Gastroenterol 2002:97:1415-20.

53. Achkar JP, Dassopoulos T, Silverberg MS, et al. Phenotype-stratified genetic linkage study demonstrates that IBD2 is an extensive ulcerative colitis locus. Am J Gastroenterol 2006;101:572-80.

54. Targan SR, Karp LC. Defects in mucosal immunity leading to ulcerative colitis. Immunol Rev 2005; 206:296-305

55. Loftus EV Jr, Harewood GC, Loftus CG, et al. PSCIBD: a unique form of inflammatory bowel disease associated with primary sclerosing cholangitis. Gut 2005;54:91-6.

56. Geboes K. Crohn's disease, ulcerative colitis or indeterminate colitis_-how important is it to differentiate? Acta Gastroenterol Belg 2001:64:197-200.

57. Nenci A, Becker C, Wullaert A, et al. Epithelial NEMO links innate immunity to chronic intestinal inflammation. Nature 2007:446:557-61.

58. Kim SC, Tonkonogy SL, Albright CA, et al. Variable phenotypes of enterocolitis in interleukin 10-deficient mice monoassociated with two different commensal bacteria. Gastroenterology 2005;128:891-906.

59. Wehkamp J, Wang G, Kubler I, et al. The Paneth cell $\boldsymbol{\alpha}$-defensin deficiency of ileal Crohn's disease is linked to Wnt/Tcf-4. J Immunol 2007;179:3109-18.
60. Vermeire S, Pierik M, Hlavaty T, et al. Association of organic cation transporter risk haplotype with perianal penetrating Crohn's disease but not with susceptibility to IBD. Gastroenterology 2005;129:1845-53.

61. Crohn B, Ginsberg L, Oppenheimer G. Regional ileitis: a clinical and pathological entity. JAMA 1932:99:1323-1329

62. Mottet N. Intestinal histopathology of regional enteritis. In: Mottet N, ed. Histopathologic spectrum of regional enteritis and ulcerative colitis. Philadelphia: Saunders, 1971:63-107.

63. Peyrin-Biroulet L, Chamaillard M, Gonzalez F, et al. Mesenteric fat in Crohn's disease: a pathogenetic hallmark or an innocent bystander? Gut 2007;56:57783.

64. Desreumaux P, Ernst 0 , Geboes K, et al. Inflammatory alterations in mesenteric adipose tissue in Crohn's disease. Gastroenterology 1999;117:7381.

65. Colombel JF, Solem CA, Sandborn WJ, et al. Quantitative measurement and visual assessment of ileal Crohn's disease activity by computed tomography enterography: correlation with endoscopic severity and $\mathrm{C}$ reactive protein. Gut 2006:55:1561-7.

66. Maconi G, Parente F, Bollani S, et al. Factors affecting splanchnic haemodynamics in Crohn's disease: a prospective controlled study using Doppler ultrasound. Gut 1998;43:645-50

67. Danese $\mathbf{S}$, Sans $\mathrm{M}$, de la Motte $\mathrm{C}$, et al. Angiogenesis as a novel component of inflammatory bowel disease pathogenesis. Gastroenterology 2006;130:2060-73.

68. Danese S, Sans M, Spencer DM, et al. Angiogenesis blockade as a new therapeutic approach to experimental colitis. Gut 2007;56:855-62.

69. Van Kruiningen H, Colombel JF. The forgotten role of lymphangitis in Crohn's disease. Gut 2007:57:1-4.

70. Mooney EE, Walker J, Hourihane DO. Relation of granulomas to lymphatic vessels in Crohn's disease. J Clin Pathol 1995;48:335-8.

71. Irvine EJ, Marshall JK. Increased intestinal permeability precedes the onset of Crohn's disease in a subject with familial risk. Gastroenterology 2000;119:1740-4.

72. Israeli E, Grotto I, Gilburd B, et al. AntiSaccharomyces cerevisiae and antineutrophil cytoplasmic antibodies as predictors of inflammatory bowel disease. Gut 2005;54:1232-6.

73. Van Kruiningen HJ, Ganley LM, Freda BJ. The role of Peyer's patches in the age-related incidence of Crohn's disease. J Clin Gastroenterol 1997;25:470-5.

74. Consigny Y, Modigliani R, Colombel JF, et al. A simple biological score for predicting low risk of shortterm relapse in Crohn's disease. Inflamm Bowel Dis 2006:12:551-7.

75. Nikolaus S, Raedler A, Kuhbacker T, et al Mechanisms in failure of infliximab for Crohn's disease. Lancet 2000;356:1475-9.

76. Sonnenberg A, Jacobsen SJ, Wasserman $\mathbb{H}$. Periodicity of hospital admissions for inflammatory bowel disease. Am J Gastroenterol 1994;89:847-51.

77. Gebhard RL, Greenberg HB, Singh N, et al. Acute viral enteritis and exacerbations of inflammatory bowel disease. Gastroenterology 1982;83:1207-9.
78. Kangro H0, Chong SK, Hardiman A, et al. A prospective study of viral and mycoplasma infections in chronic inflammatory bowel disease. Gastroenterology 1990:98:549-53.

79. Mawdsley JE, Rampton DS. Psychological stress in IBD: new insights into pathogenic and therapeutic implications. Gut 2005:54:1481-91.

80. Olaison G, Smedh K, Sjodahl R. Natural course of Crohn's disease after ileocolic resection: endoscopically visualised ileal ulcers preceding symptoms. Gut 1992;33:331-5.

81. Rutgeerts $\mathbf{P}$, Geboes K, Vantrappen G, et al. Predictability of the postoperative course of Crohn's disease. Gastroenterology 1990;99:956-63.

82. Neut C, Bulois P. Desreumaux P, et al. Changes in the bacterial flora of the neoterminal ileum after ileocolonic resection for Crohn's disease. Am J Gastroenterol 2002:97:939-46.

83. Cameron JL, Hamilton SR, Coleman J, et al. Patterns of ileal recurrence in Crohn's disease. A prospective randomized study. Ann Surg 1992;215:546-51; discussion $551-2$.

84. D'Haens GR, Geboes K, Peeters M, et al. Early lesions of recurrent Crohn's disease caused by infusion of intestinal contents in excluded ileum Gastroenterology 1998:114:262-7.

85. Harper PH, Lee EC, Kettlewell MG, et al. Role of the faecal stream in the maintenance of Crohn's colitis. Gut 1985:26:279-84.

86. Tonelli P. [New developments in Crohn's disease: unravelling the mystery of its etiopathogenesis and its reinstatement as a surgically treatable condition. Part 3: the rational principles of surgical therapy]. Chir Ital 2000;52:335-42.

87. Darfeuille-Michaud A, Neut C, Barnich N, et al. Presence of adherent Escherichia coli strains in ileal mucosa of patients with Crohn's disease.

Gastroenterology 1998;115:1405-13.

88. Barnich N, Carvalho FA, Glasser AL, et al. CEACAM6 acts as a receptor for adherent-invasive $E$. coli, supporting ileal mucosa colonization in Crohn disease. J Clin Invest 2007;117:1566-74.

89. Orchard TR, Jewell DA. Extraintestinal manifestations: skin, joints and mucocutaneous manifestations. In: Sartor R, Sandborn WJ, eds. Kirsner's inflammatory bowel diseases. Edinburgh: Saunders, 2004:658-72.

90. Orchard TR, Chua CN, Ahmad T, et al. Uveitis and erythema nodosum in inflammatory bowel disease: clinical features and the role of HLA genes. Gastroenterology 2002;123:714-8.

91. Orchard TR, Thiyagaraja S, Welsh Kl, et al. Clinical phenotype is related to HLA genotype in the peripheral arthropathies of inflammatory bowel disease. Gastroenterology 2000;118:274-8.

92. Angulo P. Lindor K. Primary sclerosing cholangitis. In: Sartor RB, Sandborn WJ, eds. Kirsner's inflammatory bowel diseases. Edinburgh: Saunders, 2004:647-657.

93. Grant AJ, Lalor PF, Salmi M, et al. Homing of mucosal lymphocytes to the liver in the pathogenesis of hepatic complications of inflammatory bowel disease Lancet 2002:359:150-7.

94. Sandborn WJ, Hanauer SB, Rutgeerts $P$, et al. Adalimumab for maintenance treatment of Crohn's disease: results of the CLASSIC II trial. Gut 2007; 56:1232-9. 